\title{
Socioeconomic position and prognosis in premenopausal breast cancer: a population-based cohort study in Denmark
}

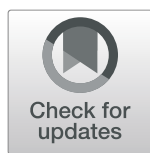

Cathrine Fonnesbech Hjorth ${ }^{1 *}$ (D), Per Damkier ${ }^{2,3}$, Bent Ejlertsen ${ }^{4,5}$, Timothy Lash ${ }^{1,6}$, Henrik Toft Sørensen ${ }^{1}$ and Deirdre Cronin-Fenton ${ }^{1}$

\begin{abstract}
Background: To investigate how socioeconomic position (SEP) influences the effectiveness of cancer-directed treatment in premenopausal breast cancer patients in terms of breast cancer recurrence and mortality.

Methods: We conducted a cohort study nested in the ProBeCaRe (Predictors of Breast Cancer Recurrence) cohort $(n=5959)$. We identified all premenopausal women aged $18-55$ years diagnosed with non-metastatic breast cancer and prescribed docetaxel-based chemotherapy in Denmark during 2007-2011. Population-based administrative registries provided data on SEP: marital status (married including registered partnership or single including divorced or widowed), cohabitation (cohabiting or living alone), education (low, intermediate, or high), income (low, medium, or high), and employment status (employed, unemployed, or health-related absenteeism). For each SEP measure, we computed incidence rates, cumulative incidence proportions (CIPs), and used Poisson regression to compute incidence rate ratios (IRRs) and 95\% confidence intervals (Cls) of recurrence and death. We stratified on estrogen receptor (ER) status/tamoxifen to evaluate interaction.

Results: Our study cohort included 2616 women; 286 (CIP 13\%) experienced recurrence and 223 (CIP 11\%) died during follow-up (median 6.6 and 7.2 years, respectively). Single women had both increased 5-year risks of recurrence (IRR 1.45, 95\% Cl 1.11-1.89) and mortality (IRR 1.83, 95\% Cl 1.32-2.52). Furthermore, we observed increased 5-year mortality in women with low education (IRR 1.49, 95\% Cl 0.95-2.33), low income (IRR 1.37, 95\% Cl 0.83-2.28), unemployment (IRR 1.61, 95\% Cl 0.83-3.13), or health-related work absenteeism (IRR 1.80, 95\% Cl 1.14-2.82), but smaller or no increased risk of recurrence. These findings were especially evident among women with ER+ tumors prescribed tamoxifen. Overall analyses (follow-up max. 10 years) provided similar results.

Conclusions: Low SEP in premenopausal women with non-metastatic breast cancer was associated with increased mortality, but not always recurrence. This suggests underdetection of recurrences in certain groups. Poor prognosis in women with low SEP, especially single women, may partly be explained by tamoxifen adherence.
\end{abstract}

Keywords: Socioeconomic position, Social inequality, Breast cancer, Survivorship, Taxanes, Docetaxel, Recurrence, Mortality, Survival analyses

\footnotetext{
* Correspondence: cfh@clin.au.dk

'Department of Clinical Epidemiology, Department of Clinical Medicine,

Aarhus University and Aarhus University Hospital, Olof Palmes Allé 43-45,

8200 Aarhus N, Denmark

Full list of author information is available at the end of the article
}

(c) The Author(s). 2021 Open Access This article is licensed under a Creative Commons Attribution 4.0 International License, which permits use, sharing, adaptation, distribution and reproduction in any medium or format, as long as you give appropriate credit to the original author(s) and the source, provide a link to the Creative Commons licence, and indicate if changes were made. The images or other third party material in this article are included in the article's Creative Commons licence, unless indicated otherwise in a credit line to the material. If material is not included in the article's Creative Commons licence and your intended use is not permitted by statutory regulation or exceeds the permitted use, you will need to obtain permission directly from the copyright holder. To view a copy of this licence, visit http://creativecommons.org/licenses/by/4.0/ The Creative Commons Public Domain Dedication waiver (http://creativecommons.org/publicdomain/zero/1.0/) applies to the data made available in this article, unless otherwise stated in a credit line to the data. 


\section{Background}

Advances in breast cancer screening and treatment have enlarged the pool of breast cancer survivors [1]. These women are at risk of breast cancer recurrence and premature death, but data on how socioeconomic position (SEP) influences this risk are scarce.

SEP has been associated with breast cancer recurrence, but most studies stem from settings of unequal healthcare access and non-uniform insurance coverage [2-6]. Furthermore, most studies focused on racial, ethnic, or insurance-related disparities [2-5]. Countries with taxfunded healthcare could be expected to offer equal treatment and follow-up after cancer irrespective of SEP. However, in Nordic countries, health inequality persists despite the build-up of the welfare states (also called the Nordic paradox) [7]. Studies set in Denmark, a country with tax-funded healthcare, report increased risks of breast cancer recurrence (and other cancer types) among patients with low education and in those living alone [8], and a higher 5-year mortality in women with lower education and income $[9,10]$, even after adjusting for tumor characteristics, treatment, and comorbidities [11, 12]. The same tendency has been observed in other European countries [12]. Thus, SEP-related disparities in breast cancer prognosis are evident even in populations with universal healthcare access.

The potential influence of SEP on breast cancer prognosis may differ according to patients' characteristics. Scandinavian studies show increased mortality in women with breast cancer with low SEP aged below 50 years (assumed premenopausal) [13-15], whereas no such association was seen in their older counterparts [13, 14]. Moreover, stage-specific survival has improved less over time in Norwegian women with low SEP, compared to women with high SEP [15].

Breast tumors in premenopausal women often have poor prognostic characteristics-higher stage and grade and estrogen receptor (ER) negative [16, 17]. Accordingly, most premenopausal women are recommended taxanebased chemotherapy, followed by up to 10 years of tamoxifen therapy for those with ER+ tumors, whereas postmenopausal women to a greater extent can forego chemotherapy [18-20]. Yet, studies on breast cancer prognosis according to SEP did not distinguish pre- from postmenopausal breast cancer [8-11], lacked treatmentspecific information $[8,15,21,22]$, failed to stratify by ER status $[8-11,14,15,21,22]$, and included patients with metastatic breast cancer [11, 13, 14, 22, 23]. We therefore investigated the association between individual-level SEP and breast cancer recurrence and overall mortality in a contemporary cohort of Danish premenopausal women with non-metastatic breast cancer, treated with taxanebased chemotherapy. We evaluated interaction by ER status and associated tamoxifen therapy.

\section{Methods}

\section{Setting and design}

This nationwide population-based cohort study was conducted in Denmark, a country with unfettered access to tax-financed healthcare [24]. All Danish citizens and legal residents have a Civil Personal Registration number, which facilitates individual-level data linkage across all Danish administrative and health registries [24]. Since 1977, clinical guidelines for diagnosis, treatment, and follow-up in breast cancer patients in Denmark have been directed by the Danish Breast Cancer Group (DBCG), informed by international research and DBCG clinical trials [25]. In their clinical database, DBCG registers follow-up data for all patients with invasive breast cancer [26]. Completeness is achieved by means of data linkage to the Danish Pathology Registry recording first primary tumors [26], and electronic reporting from all Danish pathology departments, supported by a query reminder system [27]. DBCG's follow-up data includes data on recurrences detected at follow-up exams that until 2015 took place semi-annually in the first 5 years and annually in the next 5 years for patients on active treatment [28]. Since 2015, patients have been offered structured follow-up at 12 and 18 months and then given a choice of physician-, nurse-, or patient-led follow-up for a total of 10 years. However, all breast cancer survivors are referred to a mammography screening program and are expedited through diagnostic work-up in the case of new symptoms [29].

\section{Study cohort}

We nested our study cohort in the ProBeCaRe (Predictors of Breast Cancer Recurrence) cohort [17], which includes premenopausal women diagnosed with incident non-metastatic breast cancer in Denmark during 20022011, registered in the DBCG clinical database. We restricted the study cohort to women aged $18-55$ years diagnosed during 2007-2011 and treated with adjuvant chemotherapy, as current guideline treatment including taxane-based chemotherapy was introduced on 1 January 2007.

\section{Data collection from Danish registries}

We collected SEP information from administrative registries, marital status and cohabitation from the Danish Civil Registration System [24], income from the Danish Income Statistics Registry [30], highest completed education from the Population's Education Registry [31] and social security payment data from the Danish Register for Evaluation of Marginalization to assess employment status [32]. From the DBCG clinical database, we obtained information on age, tumor characteristics, and treatments, and date of recurrence or other malignancies. Last, we retrieved information on emigration from 
Statistics Denmark, dates and cause of death from the Cause of Death Registry [33], and comorbidities from the Danish National Patient Registry [34].

\section{Analytic variables}

Covariate assessment according to the underlying time scale is graphically illustrated in Additional file 1: Figure S1 [35].

\section{Socioeconomic position}

We collected information on SEP at breast cancer diagnosis, or during the 2 years preceding diagnosis, to avoid reverse causation [36]. We categorized marital status at diagnosis as married, including women living in a registered partnership, or single, including never married, divorced, or widowed. We considered cohabitation status in the calendar year before the year of breast cancer diagnosis as cohabiting (living with a partner) or living alone. Income reflected the total household income minus total taxes accounting for the number of persons in the household. We defined income as the average income in the two preceding calendar years using sample quartiles $(\mathrm{Q})$ categorized into low $(<\mathrm{Q} 1)$, medium $(\mathrm{Q} 1-$ Q2), and high (< Q3). We categorized education into low ( 9-11 years of schooling), intermediate $(\sim 12-13$ years of schooling), and high ( 14-20 year of schooling) (Additional file 1: Figure S2). Last, we collected weekly employment data 3-12 months before breast cancer diagnosis and categorized it by the main presence of employment, unemployment, or health-related absenteeism (Additional file 1: Table S1). Please see Additional file 1: Figure S3 for a detailed description of the interrelated relationships between the SEP measures and their relationship with other covariates.

\section{Recurrence and death}

We used the DBCG's definition of breast cancer recurrence as locoregional or distant recurrence or contralateral breast cancer diagnosed up to 10 years after diagnosis [37]. We defined overall mortality as deaths from any cause, as deaths in these young women were likely related to breast cancer.

\section{Covariates}

We included a comprehensive set of covariates: age, pathological stage I-III according to the TNM (tumor, node, metastasis) staging system [38], grade 1-3 in ductal and lobular tumors, received surgery type categorized as lumpectomy (including intended radiation therapy) or mastectomy, ER status, human epidermal growth factor 2 (HER2) status, and triple negative breast cancer if tumors were ER-, HER2-, and had negative or missing progesterone receptor status. All women with ER+ tumors were prescribed tamoxifen therapy, as we only included women on guideline treatment protocols [17]. We used the Charlson comorbidity index (CCI) [39] to summarize comorbidities diagnosed before breast cancer diagnosis (Additional file 1: Table S2).

\section{Statistical analyses}

We described the study cohort calculating distributions and person years across all covariates, including missings. Follow-up time began 6 months after the date of diagnosis (date of surgery), equal to the time period during which most women in our cohort would likely have completed chemotherapy. We followed the women until recurrence/death, emigration, or 31 December 2016. When examining recurrence, we censored at other malignancy, last follow-up visit, or end of DBCG protocol (maximum 10 years). We calculated median follow-up time (incorporating the 6 months after surgery) including the interquartile range (IQR). To assess the incidences of recurrence and death, we calculated cumulative incidence proportions (CIPs) and presented these using the Nelson-Aalen estimator, treating death as a competing risk when examining recurrence. We calculated incidence rates (IRs) per 1000 person years by dividing the number of events by risk time and used Poisson regression models to compute crude and directed acyclic graph (DAG) [40] adjusted incidence rate ratios (IRR) (Additional file 1: Figure S3). We stratified by ER status to evaluate interaction. Post hoc, we evaluated potential interaction by stratifying models of marital status by cohabitation. All statistical analyses were conducted using SAS software, Version 9.4.

\section{Sensitivity analyses}

To account for potential underreporting of recurrence [41], we changed our definition of recurrence to also include breast cancer-specific mortality (BCSM) (in those with no recurrence registered), expecting those to be underreported recurrences. We also examined BCSM separately to validate our mortality results. Last, we changed the time frame of employment status assessment to 1-3 months before breast cancer diagnosis.

\section{Results}

The ProBeCaRe cohort included 5959 premenopausal women diagnosed during 2002-2011; 2979 were diagnosed after 1 January 2007. After exclusions, our study cohort included 2616 women (Additional file 1: Figure S4). Table 1 illustrates the characteristics of the study cohort. A total of 286 women (CIP 13\%) were diagnosed with a recurrence over a median 6.6 years (IQR 5.4-7.9) of follow-up; $97 \%(n=227)$ of these were diagnosed in the first 5 years (CIP 9\%). Two hundred twenty-three women (CIP 11\%) died during a median follow-up of 
Table 1 Descriptive patient characteristics of premenopausal women diagnosed with non-metastatic breast cancer during $2007-2011$

\begin{tabular}{|c|c|c|c|}
\hline & $\mathbf{N}$ & $\%$ & Person years \\
\hline Overall & 2616 & 100 & 15605 \\
\hline \multicolumn{4}{|l|}{ Marital status $^{a}$} \\
\hline Married & 1709 & 65.3 & 10395 \\
\hline Single & 907 & 34.7 & 5210 \\
\hline \multicolumn{4}{|l|}{ Cohabitation } \\
\hline Living with partner & 2006 & 76.7 & 12073 \\
\hline Living alone & 588 & 22.5 & 3394 \\
\hline Missing & 22 & 0.8 & 139 \\
\hline \multicolumn{4}{|l|}{ Household income ${ }^{b}$} \\
\hline Low & 651 & 24.9 & 3808 \\
\hline Medium & 1304 & 49.8 & 7951 \\
\hline High & 652 & 24.9 & 3789 \\
\hline Missing & 9 & 0.3 & 57 \\
\hline \multicolumn{4}{|l|}{ Education level ${ }^{c}$} \\
\hline Low & 436 & 16.7 & 2587 \\
\hline Intermediate & 1107 & 42.3 & 6671 \\
\hline High & 1048 & 40.1 & 6198 \\
\hline Missing & 25 & 1.0 & 149 \\
\hline \multicolumn{4}{|l|}{ Employment status $^{d}$} \\
\hline Employed & 2212 & 84.6 & 13343 \\
\hline Unemployed & 116 & 4.4 & 654 \\
\hline Health-related absenteeism & 280 & 10.7 & 1561 \\
\hline Not resident in Denmark & 8 & 0.3 & 48 \\
\hline \multicolumn{4}{|l|}{ Age at diagnosis ${ }^{e}$} \\
\hline$<35$ years & 190 & 7.3 & 1064 \\
\hline $35-44$ years & 990 & 37.8 & 5954 \\
\hline $45-55$ years & 1436 & 54.9 & 8587 \\
\hline \multicolumn{4}{|l|}{ CCl score } \\
\hline 0 & 2279 & 87.1 & 13702 \\
\hline $1-2$ & 252 & 9.6 & 1457 \\
\hline 3 or more & 85 & 3.2 & 446 \\
\hline \multicolumn{4}{|l|}{ Surgery type } \\
\hline Mastectomy & 1019 & 39.0 & 5923 \\
\hline Lumpectomy $^{f}$ & $\leq 1600$ & & \\
\hline Missing & $\leq 5$ & & \\
\hline \multicolumn{4}{|l|}{ ER status } \\
\hline Negative & 573 & 21.9 & 3093 \\
\hline Positive & 2043 & 78.1 & 12512 \\
\hline \multicolumn{4}{|l|}{ HER2 status } \\
\hline Negative & 1971 & 75.3 & 11670 \\
\hline Positive & 479 & 18.3 & 2829 \\
\hline Unknown & 166 & 6.3 & 1107 \\
\hline
\end{tabular}


Table 1 Descriptive patient characteristics of premenopausal women diagnosed with non-metastatic breast cancer during $2007-2011$ (Continued)

\begin{tabular}{|c|c|c|c|}
\hline & $\mathrm{N}$ & $\%$ & Person years \\
\hline \multicolumn{4}{|l|}{ TNBC } \\
\hline No & 2218 & 84.8 & 13503 \\
\hline Yes & 296 & 11.3 & 1602 \\
\hline Unknown & 102 & 3.9 & 501 \\
\hline \multicolumn{4}{|c|}{ Positive lymph nodes } \\
\hline None & 1045 & 39.5 & 6374 \\
\hline $1-2$ & 1125 & 43.0 & 6840 \\
\hline 3 or more & 434 & 16.6 & 2340 \\
\hline Missing & 12 & 0.5 & 51 \\
\hline \multicolumn{4}{|l|}{ Tumor size (mm) } \\
\hline$\leq 20$ & $\leq 1428$ & & \\
\hline $21-50$ & 1096 & 41.9 & 6462 \\
\hline 51 or above & 88 & 3.4 & 474 \\
\hline Missing & $\leq 5$ & & \\
\hline \multicolumn{4}{|l|}{ TNM stage $^{9}$} \\
\hline Stage I & 671 & 25.6 & 4079 \\
\hline Stage II & 1463 & 55.9 & 8932 \\
\hline Stage III & 462 & 17.7 & 2494 \\
\hline Missing & 20 & 0.8 & 100 \\
\hline \multicolumn{4}{|c|}{ Pathological grade ${ }^{h}$} \\
\hline Grade 1 & 393 & 15.0 & 2498 \\
\hline Grade 2 & 1091 & 41.7 & 6716 \\
\hline Grade 3 & 860 & 32.9 & 4806 \\
\hline Not graded & 240 & 9.2 & 1404 \\
\hline Missing & 32 & 1.2 & 181 \\
\hline
\end{tabular}

${ }^{a}$ Married included women living in a registered partnership; single included never married, divorced, or widowed. ${ }^{\mathrm{b}}$ Based on sample quartiles categorized into low (<Q1), medium (Q1-Q2), and high $(\mathrm{Q} 3<)$. ‘ Low: primary school ( 9-11 years of schooling); intermediate: upper secondary school ( 12-13 years of schooling); high: tertiary education ( 14-20 year of schooling). ${ }^{d}$ Employed included women receiving no benefits and women on maternity leave; unemployment included women receiving non-health related unemployment benefits; health-related absenteeism included women receiving a health-related social benefit. ${ }^{\mathrm{e}}$ Median age was 45 years (IQR: 41-49). ${ }^{f}$ Including intention to treat radiotherapy. If lumpectomy was followed by mastectomy, the date of lumpectomy was used ${ }^{9}$ Derived from tumor size and lymph node status. ${ }^{\mathrm{h}}$ Ductal and lobular tumors. Other were not graded. In accordance with Danish law, cell sizes with fewer than five observations and cells permitting back calculation are reported in aggregate

Abbreviations: CCI Charlson Comorbidity Index, ER estrogen receptor, HER2 human epidermal growth factor 2, TNBC triple negative breast cancer, TNM tumor, node, metastasis

7.2 years (IQR 6.0-8.6), 66\% $(n=148)$ within 5 years (CIP 6\%) (Additional file 1: Figure S5).

\section{Socioeconomic position}

Figure 1 illustrates CIP curves of recurrence and mortality according to SEP. Figures 2 and 3 present IRs and IRRs of recurrence and mortality by SEP, at 5 years, and up to 10 years after breast cancer diagnosis. Unless otherwise stated, the IRRs presented below represent 5year DAG-adjusted estimates.

Compared with married women, single women had poorer prognosis (IRR recurrence 1.45, 95\% CI 1.111.89 and IRR mortality $1.83,95 \%$ CI $1.32-2.52$ ). Stratification suggested effect measure modification by ER status whereby single women with ER+ tumors had increased risk of recurrence (IRR 1.60, 95\% CI 1.17-2.20) and mortality (1.96, 95\% CI 1.35-2.84) (Additional file 1: Tables S3-S4). We observed increased crude recurrence and mortality risk in women living alone, but estimates attenuated after adjustment. Although estimates were imprecise, the recurrence risk remained increased in single women regardless of cohabitation status, but was higher in singles living alone than in cohabiting single women. In contrast, the mortality in cohabiting single women was higher than in single women living alone (data not shown).

We observed increased mortality in women with low education (IRR 1.49, 95\% CI 0.95-2.33). Women with 


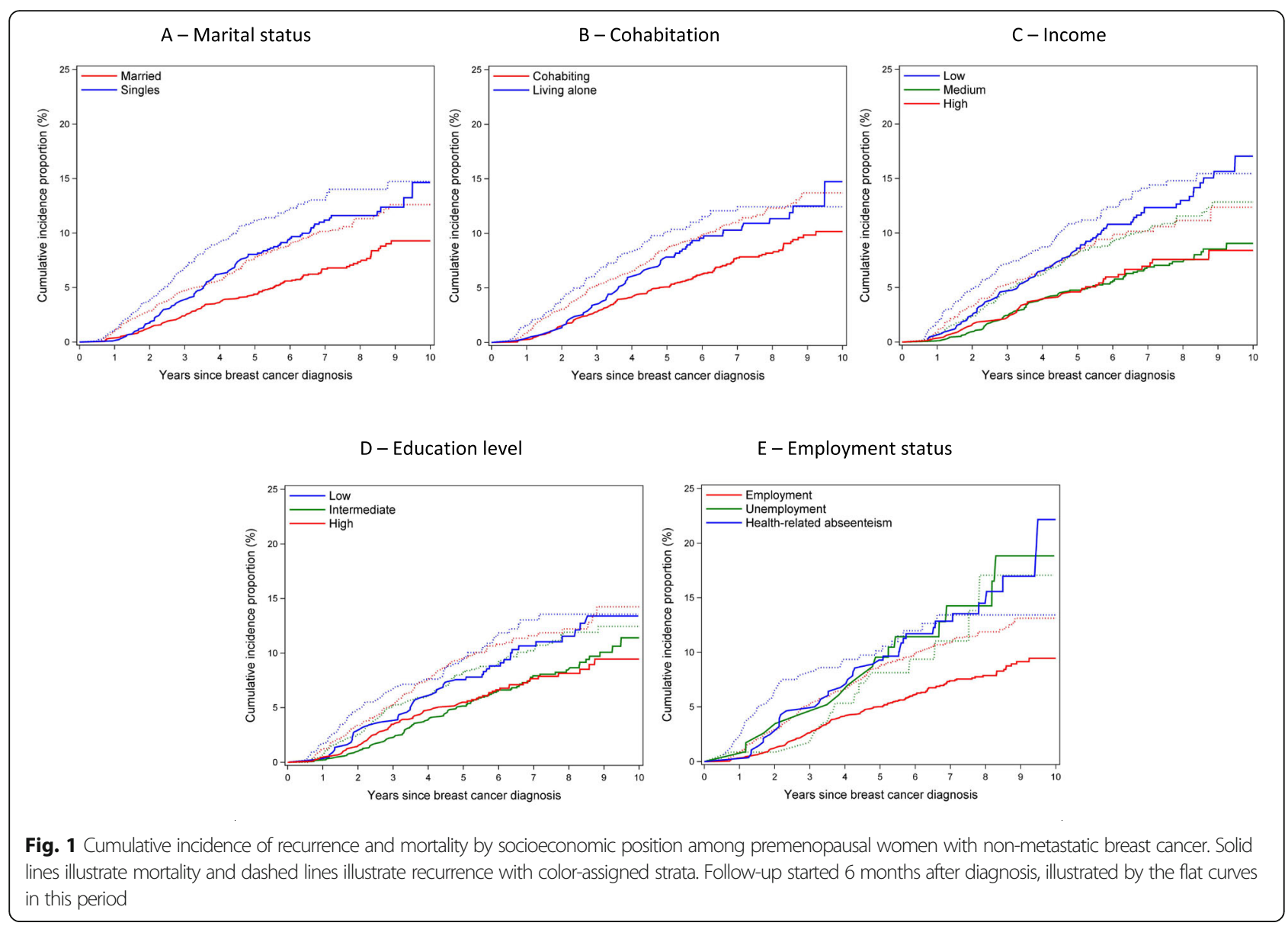

$\mathrm{ER}+$ tumors and low income had increased risk of recurrence (IRR 1.28, 95\% CI 0.82-2.00) and mortality (IRR 1.57, 95\% CI 0.91-2.69) (Additional file 1: Table S4).

Compared with employed women, women with health-related absenteeism had slightly elevated recurrence risk (IRR 1.22, 95\% CI 0.80-1.84), and the mortality was 2-fold higher in those with ER+ tumors (IRR 1.99, 95\% CI 1.20-3.28), which was not seen in ER tumors. Mortality was increased in unemployed women with ER+ tumors, but estimates were imprecise (IRR 2.15, 95\% CI 1. 08-4.26).

Pooling recurrences with BCSMs $(n=343)$ increased the IRR in unemployed women (IRR 1.53, 95\% CI 0.962.45) (Additional file 1: Figure S6). Restricting to BCSM $(n=203)$ marginally increased IRRs in all low SEP groups, with the most pronounced change among unemployed women (IRR 2.17, 95\% CI 1.23-3.83) (Additional file 1: Figure S7). Mortality risk remained stable in women with health-related absenteeism and was null in unemployed when we altered employment status assessment (Additional file 1: Figure S8).

\section{Discussion}

Single women had increased recurrence risk and mortality compared with their married counterparts; this was mainly seen in those with ER+ tumors. We observed increased mortality in women who had low education, low income, were unemployed, or had health-related absenteeism, especially among those with ER+ tumors.

As outlined by Green at al [42], SEP consists of several elements, which cover separate aspects of SEP, that overlap in a shared core dimension of SEP. One single measure may not completely cover the underlying SEP, but our similar findings across several SEP measures support an impact of SEP on breast cancer prognosis, especially mortality. Although we used administrative data assuring high validity, some misclassification of SEP was possible, and other categorizations could possibly have shed light on other aspects of SEP. Some of our estimates were imprecise, but across SEP measures, the lower bound of the $95 \% \mathrm{CI}$ had the same direction, supporting that the core dimension of SEP may be associated with prognosis. A slightly larger sample size would have increased the precision of our estimates.

Our findings were partly modified by ER status, similar to findings reported by others [43]. A previous study set 


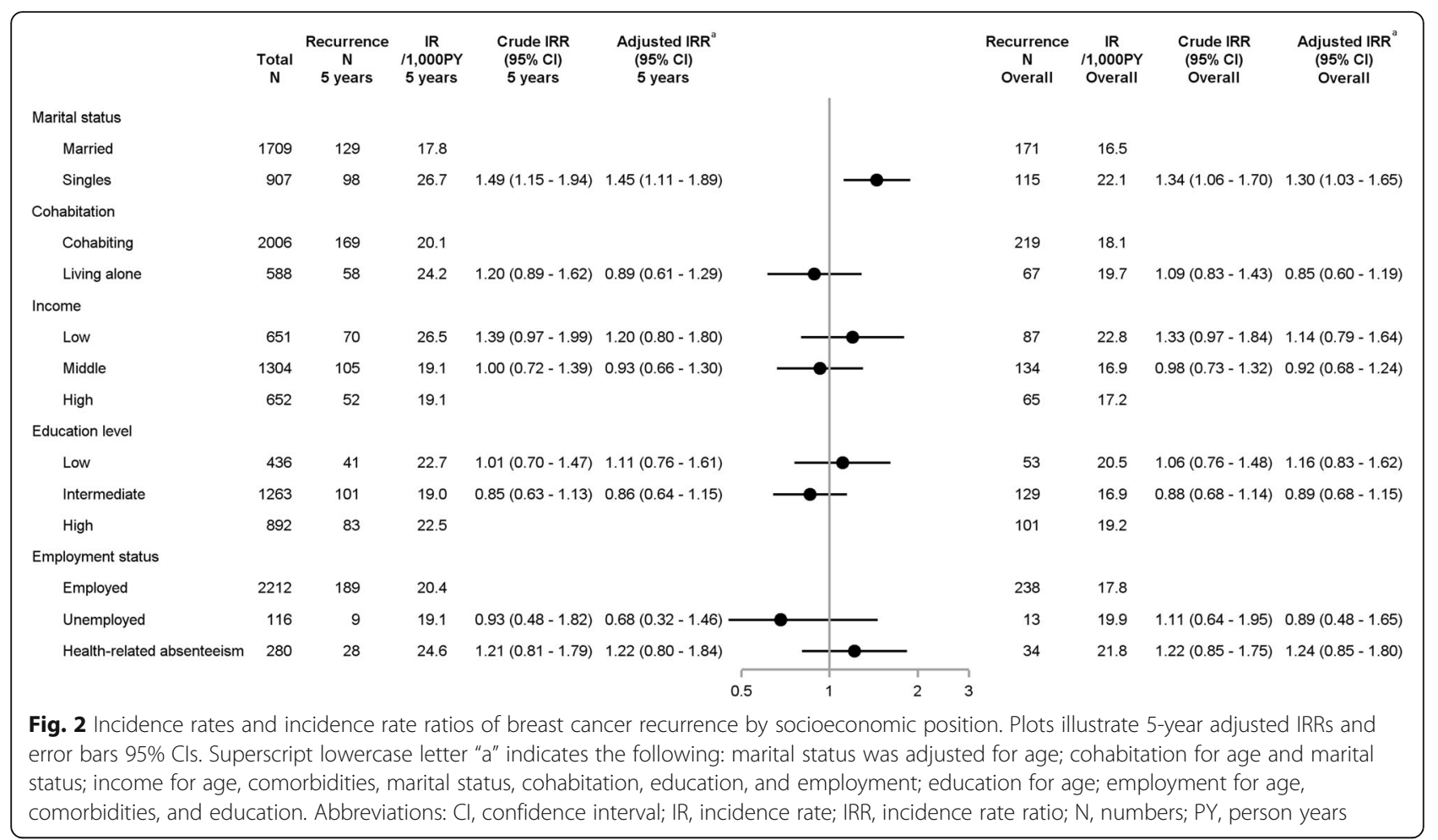

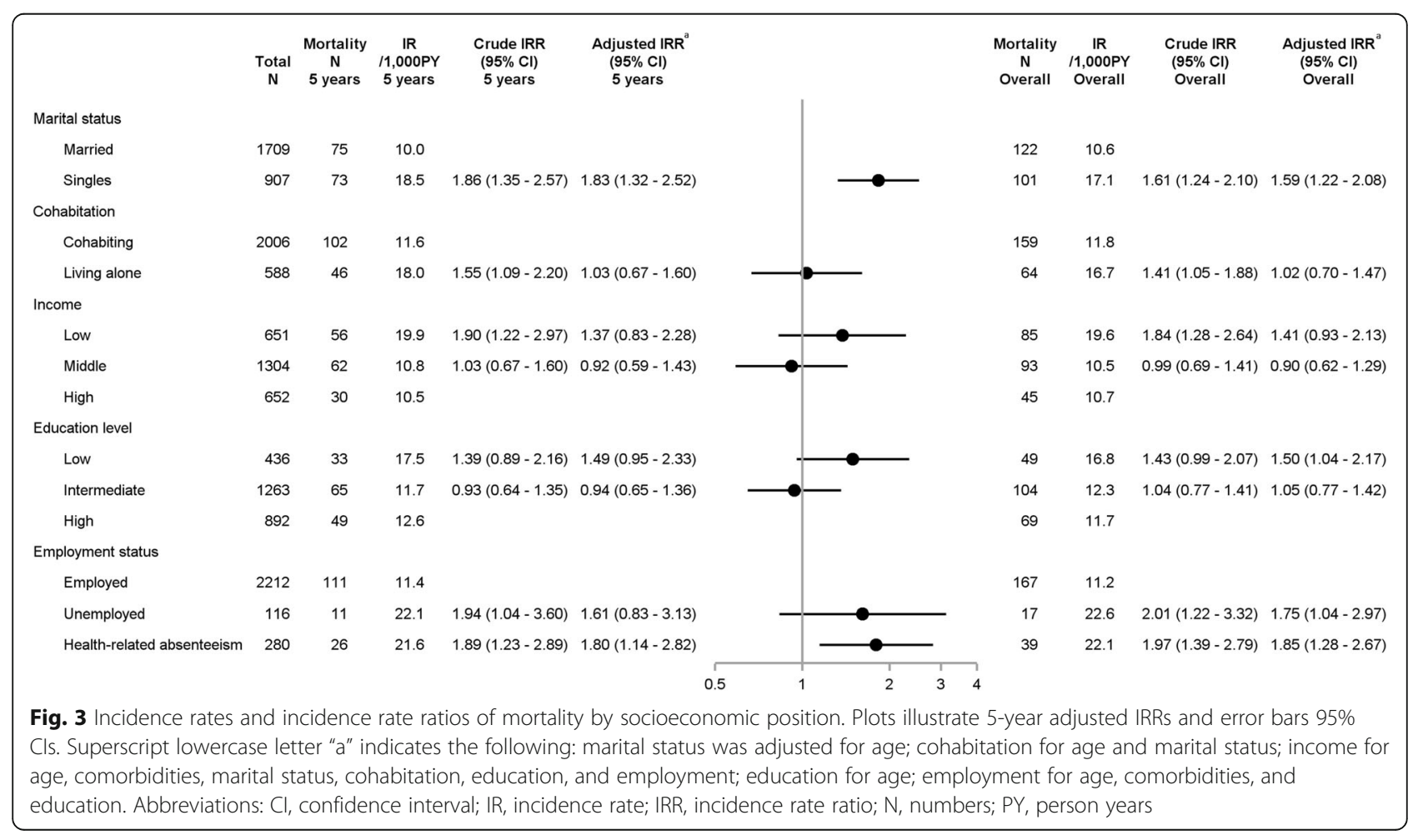


in the ProBeCaRe cohort showed that $22 \%$ of women with ER+ tumors prematurely discontinued their tamoxifen therapy [44]. Early discontinuation increased the recurrence risk, and lower adherence was observed in single women [44]. Tamoxifen is sometimes associated with bothersome side effects, which may impact treatment adherence [45]. Likewise, taxanes incite a wide range of side effects leading to treatment disruption and/or dose reduction, limiting treatment effectiveness [46]. Social support from a partner might influence treatment compliance, particularly among women suffering from side effects. This may have impacted our findings of higher recurrence and mortality among single women. We did not have information on chemotherapy adherence. A study in postmenopausal women shows that discontinuation of chemotherapy is most often due to comorbidities or age, and rarely based on patient request [47]. Our cohort of young patients had a low prevalence of comorbidities and a long life expectancy. We therefore expect it to be rare for them to discontinue a time-limited treatment such as chemotherapy. Still, any discontinuation of therapy could differ by SEP and could be more likely among patients with low SEP $[44,48]$. This could have influenced our findings.

Similar to our crude estimates, the aforementioned Danish study on breast cancer recurrence reported lower risks in women living alone, also after adjustment for age, education level, comorbidity, calendar period, tumor and lymph node stage, and adjuvant therapy (chemotherapy and/or radiotherapy) [8]. However, their findings may be affected by residual confounding from other dimensions of SEP, which were not incorporated in their study (e.g., income and employment). We note that adjustment for other SEP measures attenuated our estimates. The previous Danish study used a validated algorithm capturing recurrences in Danish registries [49]. However, their adjusted estimates for education were similar to ours, suggesting non-differentially underreporting in DBCG across SEP categories. As such, our relative estimates may not be affected by the underreported recurrences in DBCG.

Our sensitivity analyses confirmed that deaths in this young population were mainly due to breast cancer. Accordingly, the equivalent mortality, but not recurrence risk, especially across levels of education and employment, may indicate underdetection of recurrences in deprived groups. Danish women with low SEP are less likely to be referred to, and to attend, cancer rehabilitation programs $[50,51]$, including mammography screening [52]. Recurrences may therefore be underdetected in women with low SEP if they opted out of the follow-up programs. These findings may also enhance the understanding of SEP-related disparities in non-tax-funded healthcare settings, by indicating that inequality in cancer survivorship extend beyond obvious factors like insurance coverage.

Several issues should be considered when interpreting our findings. The main strength of this study is the use of routinely collected registry data, with high validity and completeness [24]. The clinical data registered in the DBCG have high validity $[41,53]$, and the expected direction and association of prognostic characteristics, e.g. stage, were evident (data not shown). Nonetheless, based on a previous study validating DBCG data against medical records [41], our observed incidence of recurrence may be underestimated.

We used registry-based individual-level measures of SEP, with high validity and completeness [24, 30-32]. As such, our classification of marital status had high validity for marriage and registered relationships [24], but does not capture unregistered cohabitation, which is a common way of living in Denmark [54]. We therefore included cohabitation, which, besides marriage and registered partnerships, also considers two persons of different genders at the same address as cohabiting partners if the age difference is less than 15 years, or if they have children. As such, women with a female roommate or partner would be registered as living alone, leading to misclassification. We identified a group of cohabiting singles; this may include women in unregistered partnerships or divorced women living with their old or a new partner. However, the suggested mediation of cohabitation on marital status was imprecise and presumably a chance finding.

Our findings may be prone to unmeasured confounding. Lundqvist et al. [12] found that reproductive and lifestyle factors contributed to the association between SEP and mortality in breast cancer patients. Naturally, reproductive factors in singles may differ to those in married women. Although we incorporated $\mathrm{CCI}$ as a proxy for patient health, we had no information on lifestyle factors, e.g., smoking and diet, which may have influenced our observed associations. However, reproductive and behavioral factors in relation to breast cancer are more relevant in postmenopausal women [55]. The CCI does not include mental disorders, which account for $50 \%$ of all long-term sick leave in Denmark [56]. Mental disorders before breast cancer are associated with early retirement [57], suggesting exacerbation after diagnosis. This may have contributed to our findings in women with healthrelated absenteeism.

The average time from recurrence to death varies by breast cancer subtypes, being longer in women with ER+ disease ( $\sim 2-3$ years) and shorter in women with ER- $(\sim$ 1-2 years) [58]. Thus, we may have underestimated the 5 -year recurrence incidence in our sensitivity analysis where we considered BCSMs as recurrences. 
Last, docetaxel was the taxane-compound used during the study period, but this has gradually been replaced by paclitaxel due fewer adverse effects [26]. Docetaxel and paclitaxel exert similar structural and microtubulestabilizing effects [59] and have similar effectiveness [60]. Therefore, our findings are relevant to current clinical practice.

\section{Conclusions}

In summary, premenopausal women who were single at breast cancer diagnosis were more likely to develop recurrence or mortality. Women with low income, low education, unemployment, or health-related absenteeism also had higher mortality. This suggests that detection of recurrent breast cancer may be differential depending on SEP. Our findings were especially evident among women with ER+ tumors, suggesting that poor tamoxifen adherence may have contributed to our findings. Therefore, supportive care to these women may help them derive optimal benefit from cancer treatment. To assist this, an important future perspective is to better understand the mechanisms underlying this inequality.

\begin{abstract}
Abbreviations
BCSM: Breast cancer-specific mortality; CCl: Charlson comorbidity index; Cl: Confidence interval; CIP: Cumulative incidence proportion; DAG: Directed acyclic graph; DBCG: Danish Breast Cancer Group; ER: Estrogen receptor; HER2: Human epidermal growth factor 2; IR: Incidence rate; IRR: Incidence rate ratio; IQR: Interquartile range; PY: Person years; SEP: Socioeconomic position; TNBC: Triple negative breast cancer; TNM: Tumor, node, metastasis, ProBeCaRe: Predictors of Breast Cancer Recurrence; Q: Quartile
\end{abstract}

\section{Supplementary Information}

The online version contains supplementary material available at https://doi. org/10.1186/s12916-021-02108-z.

Additional file 1: Figure S1. Covariate assessment. Figure S2.

Education categorization. Figure S3. DAG. Figure S4. Flow diagram. Figure S5. CIP-curve. Figure S6. Sensitivity analysis: Recurrence incl. BCSM. Figure S7. Sensitivity analysis: BCSM, Figure S8. Sensitivity analysis: Employment. Table S1. Employment status. Table S2. Charlson Comorbidity Index. Table S3. Recurrence by ER status. Table S4. Mortality by ER status.

\section{Acknowledgements}

The authors thank Anders Kjærsgaard (Biostatistician, Department of Clinical Epidemiology, Aarhus University Hospital) for providing statistical support. Additionally, the authors thank the Danish Breast Cancer Group for access to its registry data.

\section{Authors' contributions}

CFH: conceptualization, methodology, formal analysis, investigation, writing - original draft, visualization, funding acquisition. PD: conceptualization, methodology, writing-review and editing, supervision. BE: resources, writing — review and editing. TL: conceptualization, methodology, resources, writing - review and editing, supervision, project administration. HTS: methodology, writing — review and editing, project administration. DCF: conceptualization, methodology, resources, writing —original draft, writing — review and editing, supervision, project administration, funding acquisition. All authors read and approved the final manuscript.

\section{Funding}

This project has received funding from the Danish Cancer Society to DCF [R167-A11045-17-S2] and from Aarhus University to CFH.

\section{Availability of data and materials}

The data in the present manuscript derive from nationwide, populationbased administrative and medical registries, linked anonymously using a personalized identifier. Procedures for accessing the data will be available from the corresponding author.

\section{Declarations}

Ethics approval and consent to participate

We managed all data according to the World Medical Association's Declaration of Helsinki, and the study was approved by the Danish Data Protection Agency (AU 2016-051-000001, \#994), the Regional Ethics Committee (Record no. 1-10-72-4-18), and the Danish Breast Cancer Group (DBCG2019-08-20). The use of registry-based data for scientific studies in Denmark requires no consent from the participants.

\section{Consent for publication}

Not applicable.

\section{Competing interests}

Department of Clinical Epidemiology, Aarhus University Hospital and Aarhus University, receives funding for other studies from the European Medicines Agency and companies in the form of research grants to (and administered by) Aarhus University. None of these studies have any relation to the present study.

\section{Author details}

${ }^{1}$ Department of Clinical Epidemiology, Department of Clinical Medicine, Aarhus University and Aarhus University Hospital, Olof Palmes Allé 43-45, 8200 Aarhus N, Denmark. ²Department of Clinical Biochemistry and Pharmacology, J.B. Winsløvs vej 4, Odense University Hospital, 5000 Odense, Denmark. ${ }^{3}$ Department of Clinical Research, Winsløwparken 19, University of Southern Denmark, 5000 Odense, Denmark. Danish Breast Cancer Group, Blegdamsvej 9, 2100 Copenhagen, Denmark. ${ }^{5}$ Department of Oncology, University of Copenhagen, Blegdamsvej 9, Rigshospitalet, 2100 Copenhagen, Denmark. ${ }^{6}$ Department of Epidemiology, Rollins School of Public Health, Emory University, 1518 Clifton Rd, Atlanta, GA 30322, USA.

Received: 15 June 2021 Accepted: 26 August 2021

Published online: 30 September 2021

\section{References}

1. Park J-H, Anderson WF, Gail MH. Improvements in US breast cancer survival and proportion explained by tumor size and estrogen-receptor status. J Clin Oncol Off J Am Soc Clin Oncol. 2015;33(26):2870-6. https://doi.org/10.1200/ JCO.2014.59.9191.

2. Obeng-Gyasi S, Asad S, Fisher JL, Rahurkar S, Stover DG. Socioeconomic and surgical disparities are associated with rapid relapse in patients with triplenegative breast cancer. Ann Surg Oncol. 2021. https://doi.org/10.1245/s1 0434-021-09688-3.

3. Asad S, Barcenas CH, Bleicher RJ, Cohen AL, Javid SH, Levine EG, et al. Sociodemographic factors associated with rapid relapse in triple-negative breast cancer: a multi-institution study. J Natl Compr Cancer Netw. 2021;10: $1-8$.

4. Gordon NH, Crowe JP, Brumberg J, Berger NA. Socioeconomic factors and race in breast cancer recurrence and survival. Am J Epidemiol. 1992;135(6): 609-18. https://doi.org/10.1093/oxfordjournals.aje.a116340.

5. Kabat GC, Ginsberg M, Sparano JA, Rohan TE. Risk of recurrence and mortality in a multi-ethnic breast cancer population. J Racial Ethn Health Disparities. 2017;4(6):1181-8. https://doi.org/10.1007/s40615-016-0324-y.

6. Silber JH, Rosenbaum PR, Ross RN, Reiter JG, Niknam BA, Hill AS, et al. Disparities in breast cancer survival by socioeconomic status despite medicare and medicaid insurance. Milbank Q. 2018;96(4):706-54. https://doi. org/10.1111/1468-0009.12355.

7. Mackenbach JP. Health Inequalities : Persistence and change in modern welfare states. Oxford: Oxford University Press; 2019. https://doi.org/10.1093/ oso/9780198831419.001.0001. 
8. Rasmussen $L A$, Jensen $H$, Virgilsen LF, Falborg AZ, Møller $H$, Vedsted P. Time from incident primary cancer until recurrence or second primary cancer: risk factors and impact in general practice. Eur J Cancer Care (Engl). 2019;28(5): e13123. https://doi.org/10.1111/ecc.13123.

9. Carlsen K, Høybye MT, Dalton SO, Tjønneland A. Social inequality and incidence of and survival from breast cancer in a population-based study in Denmark, 1994-2003. Eur J Cancer. 2008;44(14):1996-2002. https://doi.org/1 0.1016/j.ejca.2008.06.027.

10. Dalton SO, Ross L, Düring M, Carlsen K, Mortensen PB, Lynch J, et al. Influence of socioeconomic factors on survival after breast cancer--a nationwide cohort study of women diagnosed with breast cancer in Denmark 1983-1999. Int J Cancer. 2007;121(11):2524-31. https://doi.org/10.1 002/ijc.22979.

11. Aizer AA, Chen M-H, McCarthy EP, Mendu ML, Koo S, Wilhite TJ, et al. Marital status and survival in patients with cancer. J Clin Oncol. 2013;31(31): 3869-76. https://doi.org/10.1200/JCO.2013.49.6489.

12. Lundqvist A, Andersson E, Ahlberg I, Nilbert M, Gerdtham U. Socioeconomic inequalities in breast cancer incidence and mortality in Europe-a systematic review and meta-analysis. Eur J Public Health. 2016;26(5):804-13. https://doi.org/10.1093/eurpub/ckw070.

13. Lagerlund M, Bellocco R, Karlsson P, Tejler G, Lambe M. Socio-economic factors and breast cancer survival: a population-based cohort study (Sweden). Cancer Causes Control. 2005;16(4):419-30. https://doi.org/10.1007/ s10552-004-6255-7.

14. Trewin CB, Strand BH, Weedon-Fekjær H, Ursin G. Changing patterns of breast cancer incidence and mortality by education level over four decades in Norway, 1971-2009. Eur J Public Health. 2017;27(1):160-6.

15. Trewin CB, Johansson ALV, Hjerkind KV, Strand BH, Kiserud CE, Ursin G Stage-specific survival has improved for young breast cancer patients since 2000: but not equally. Breast Cancer Res Treat. 2020;182(2):477-89. https:// doi.org/10.1007/s10549-020-05698-z.

16. Mahmood H, Faheem M. Sana Mehmood. Association of menopausal status with pathological features of tumor in stage I to III A breast cancer patients treated with upfront modified radical mastectomy. J Cancer Prev Curr Res. 2016:4(1):1-5.

17. Collin LJ, Cronin-Fenton DP, Ahern TP, Christiansen PM, Damkier P, Ejlertsen $B$, et al. Cohort profile: the predictors of breast cancer recurrence (ProBe (aRE) premenopausal breast cancer cohort study in Denmark. BMJ Open. 2018;8(7):e021805. https://doi.org/10.1136/bmjopen-2018-021805.

18. Early Breast Cancer Trialists' Collaborative Group (EBCTCG). Comparisons between different polychemotherapy regimens for early breast cancer: meta-analyses of long-term outcome among 100000 women in 123 randomised trials. Lancet. 2012;379(9814):432-44. https://doi.org/10.1016/ S0140-6736(11)61625-5.

19. Gradishar WJ, Anderson BO, Balassanian R, Blair SL, Burstein HJ, Cyr A, et al. Breast cancer, Version 2.2018, NCCN Clinical Practice Guidelines in Oncology. J Natl Compr Cancer Netw. 2018;16(3):310-20. https://doi.org/10. 6004/jnccn.2018.0012.

20. Ejlertsen B, Jensen M-B, Mouridsen HT. Danish Breast Cancer Cooperative Group. Excess mortality in postmenopausal high-risk women who only receive adjuvant endocrine therapy for estrogen receptor positive breast cancer. Acta Oncol Stockh Swed. 2014;53(2):174-85. https://doi.org/10.3109/ 0284186X.2013.850738.

21. Gentil-Brevet J, Colonna M, Danzon A, Grosclaude P, Chaplain G, Velten M, et al. The influence of socio-economic and surveillance characteristics on breast cancer survival: a French population-based study. Br J Cancer. 2008; 98(1):217-24. https://doi.org/10.1038/sj.bjc.6604163.

22. Dasgupta P, Turrell G, Aitken JF, Baade PD. Partner status and survival after cancer: a competing risks analysis. Cancer Epidemiol. 2016;41:16-23. https:// doi.org/10.1016/j.canep.2015.12.009.

23. Hussain SK, Altieri A, Sundquist J, Hemminki K. Influence of education level on breast cancer risk and survival in Sweden between 1990 and 2004. Int Cancer. 2008;122(1):165-9. https://doi.org/10.1002/ijc.23007.

24. Schmidt M, Schmidt SAJ, Adelborg K, Sundbøll J, Laugesen K, Ehrenstein V, et al. The Danish health care system and epidemiological research: from health care contacts to database records. Clin Epidemiol. 2019;11:563-91. https://doi.org/10.2147/CLEP.S179083.

25. Møller S, Jensen M-B, Ejertsen B, Bjerre KD, Larsen M, Hansen HB, et al. The clinical database and the treatment guidelines of the Danish Breast Cancer Cooperative Group (DBCG); its 30-years experience and future promise. Acta Oncol Stockh Swed. 2008;47(4):506-24. https://doi.org/10.1080/02841860802059259.
26. Jensen $M-B$, Laenkholm A-V, Offersen BV, Christiansen P, Kroman N, Mouridsen $\mathrm{HT}$, et al. The clinical database and implementation of treatment guidelines by the Danish Breast Cancer Cooperative Group in 2007-2016. Acta Oncol. 2018:57(1):13-8. https://doi.org/10.1080/0284186X.2017.1404638.

27. Mouridsen $H$, Christiansen $P$, Jensen $M-B$, Laenkholm A-V, Flyger $H$, Offersen $B$, et al. Provision of data from the clinical database and of biological material from the tumor bank of the Danish Breast Cancer Cooperative Group 2008-2017. Acta Oncol. 2018;57(1):154-6. https://doi.org/10.1080/02 84186X.2017.1403039.

28. Christiansen $P$, Bjerre $K$, Ejlertsen $B$, Jensen $M-B$, Rasmussen BB, Lænkholm $A-V$, et al. Mortality rates among early-stage hormone receptor-positive breast cancer patients: a population-based cohort study in Denmark. J Natl Cancer Inst. 2011;103(18):1363-72. https://doi.org/10.1093/jnci/djr299.

29. Danish Breast Cancer Group. Section 9: Follow-up, 11.12.2015 (Danish: Kap 9 Opfoelgning og kontrol 11.12.2015) [Internet]. 2015. Available from: https:// dbcg.dk/PDF/Kap_9_Opfoelgning_og_kontrol-11.12.2015.pdf.

30. Baadsgaard M, Quitzau J. Danish registers on personal income and transfer payments. Scand J Public Health. 2011;39(7_suppl):103-5.

31. Jensen VM, Rasmussen AW. Danish Education Registers. Scand J Public Health. 2011;39(7 Suppl):91-4. https://doi.org/10.1177/1403494810394715.

32. Hiollund $\mathrm{NH}$, Larsen FB, Andersen JH. Register-based follow-up of social benefits and other transfer payments: accuracy and degree of completeness in a Danish interdepartmental administrative database compared with a population-based survey. Scand J Public Health. 2007;35(5):497-502. https:// doi.org/10.1080/14034940701271882.

33. Helweg-Larsen K. The Danish Register of Causes of Death. Scand J Public Health. 2011;39(7 Suppl):26-9. https://doi.org/10.1177/1403494811399958.

34. Schmidt M, Schmidt SAJ, Sandegaard JL, Ehrenstein V, Pedersen L, Sørensen HT. The Danish National Patient Registry: a review of content, data quality, and research potential. Clin Epidemiol. 2015;7:449-90. https://doi.org/10.214 7/CLEP.S91125.

35. Schneeweiss S, Rassen JA, Brown JS, Rothman KJ, Happe L, Arlett P, et al. Graphical depiction of longitudinal study designs in health care databases. Ann Intern Med. 2019:170(6):398-406.

36. Hoffmann R, Kröger H, Pakpahan E. Pathways between socioeconomic status and health: does health selection or social causation dominate in Europe? Adv Life Course Res. 2018;36:23-36. https://doi.org/10.1016/j.alcr.2 018.02.002.

37. Christiansen P, Al-Suliman N, Bjerre K, Møller S. Danish Breast Cancer Cooperative Group, recurrence pattern and prognosis in low-risk breast cancer patients--data from the DBCG 89-A programme. Acta Oncol Stockh Swed. 2008;47(4):691-703. https://doi.org/10.1080/02841860802056594.

38. Amin MB, American Joint Committee on Cancer, American Cancer Society, editors. AJCC cancer staging manual. Eight edition/editor-in-chief, Mahul B. Amin, MD, FCAP ; editors, Stephen B. Edge, MD, FACS [and 16 others] ; Donna M. Gress, RHIT, CTR-Technical editor ; Laura R. Meyer, CAPMManaging editor. Chicago IL: American Joint Committee on Cancer, Springer; 2017. p. 1024.

39. Charlson ME, Pompei P, Ales KL, Mackenzie CR. A new method of classifying prognostic comorbidity in longitudinal studies: development and validation. J Chronic Dis. 1987:40(5):373-83. https://doi.org/10.1016/0021-9681(87)90171-8.

40. Textor J, van der Zander B, Gilthorpe MS, Liskiewicz M, Ellison GT. Robust causal inference using directed acyclic graphs: the R package 'dagitty'. Int J Epidemiol. 2016;45(6):1887-94.

41. Cronin-Fenton DP, Kjærsgaard A, Ahern TP, Mele M, Ewertz M, HamiltonDutoit S, et al. Validity of Danish Breast Cancer Group (DBCG) registry data used in the predictors of breast cancer recurrence (ProBeCaRe) premenopausal breast cancer cohort study. Acta Oncol. 2017;56(9):1155-60. https://doi.org/10.1080/0284186X.2017.1327720.

42. Green MJ, Popham F. Interpreting mutual adjustment for multiple indicators of socioeconomic position without committing mutual adjustment fallacies. BMC Public Health. 2019:3:19.

43. Di Salvo F, Caranci N, Spadea T, Zengarini N, Minicozzi P, Amash H, et al. Socioeconomic deprivation worsens the outcomes of Italian women with hormone receptor-positive breast cancer and decreases the possibility of receiving standard care. Oncotarget. 2017;8(40):68402-14. https://doi.org/1 0.18632/oncotarget.19447.

44. Collin LJ, Cronin-Fenton D, Ahern TP, Goodman M, McCullough LE, Waller $L A$, et al. Early discontinuation of endocrine therapy and recurrence of breast cancer among premenopausal women. Clin Cancer Res Off J Am Assoc Cancer Res. 2020. 
45. Meiser B, Wong WKT, Peate M, Julian-Reynier C, Kirk J, Mitchell G. Motivators and barriers of tamoxifen use as risk-reducing medication amongst women at increased breast cancer risk: a systematic literature review. Hered Cancer Clin Pract. 2017;20:15.

46. Abola MV, Prasad V, Jena AB. Association between treatment toxicity and outcomes in oncology clinical trials. Ann Oncol Off J Eur Soc Med Oncol. 2014;25(11):2284-9. https://doi.org/10.1093/annonc/mdu444.

47. Vogsen M, Bille C, Jylling AMB, Jensen M-B, Ewertz M. Research (AgeCare) on behalf of the A for GC. Adherence to treatment guidelines and survival in older women with early-stage breast cancer in Denmark 2008-2012. Acta Oncol. 2020;59(7):741-7. https://doi.org/10.1080/0284186X.2020.1757148.

48. Ursem CJ, Bosworth HB, Shelby RA, Hwang W, Anderson RT, Kimmick GG. Adherence to adjuvant endocrine therapy for breast cancer: importance in women with low income. J Womens Health. 2015;24(5):403-8. https://doi. org/10.1089/jwh.2014.4982.

49. Aagaard Rasmussen L, Jensen H, Flytkjær Virgilsen L, Jellesmark Thorsen LB, Vrou Offersen B, Vedsted P. A validated algorithm for register-based identification of patients with recurrence of breast cancer-Based on Danish Breast Cancer Group (DBCG) data. Cancer Epidemiol. 2019;59:129-34. https://doi.org/10.1016/j.canep.2019.01.016.

50. Dalton SO, Olsen MH, Moustsen IR, Andersen CW, Vibe-Petersen J, Johansen C. Socioeconomic position, referral and attendance to rehabilitation after a cancer diagnosis: a population-based study in Copenhagen, Denmark 2010 2015. Acta Oncol. 2019;58(5):730-6. https://doi.org/10.1080/0284186X.2019.1 582800 .

51. Holm LV, Hansen DG, Larsen PV, Johansen C, Vedsted P, Bergholdt SH, et al. Social inequality in cancer rehabilitation: a population-based cohort study. Acta Oncol Stockh Swed. 2013;52(2):410-22. https://doi.org/10.3109/02841 86X.2012.745014.

52. Jensen LF, Pedersen AF, Andersen B, Vedsted P. Identifying specific nonattending groups in breast cancer screening--population-based registry study of participation and socio-demography. BMC Cancer. 2012;12(1):518. https://doi.org/10.1186/1471-2407-12-518.

53. Jensen AR, Storm HH, Møller S, Overgaard J. Validity and representativity in the Danish Breast Cancer Cooperative Group--a study on protocol allocation and data validity from one county to a multi-centre database. Acta Oncol Stockh Swed. 2003;42(3):179-85. https://doi.org/10.1080/02841860310000737.

54. Frisch $\mathrm{M}$, Simonsen J. Marriage, cohabitation and mortality in Denmark: national cohort study of 6.5 million persons followed for up to three decades (1982-2011). Int J Epidemiol. 2013;42(2):559-78. https://doi.org/10.1 093/ije/dyt024.

55. Menvielle G, Leclerc A, Chastang J-F, Luce D. Social inequalities in breast cancer mortality among French women: disappearing educational disparities from 1968 to 1996. Br J Cancer. 2006;94(1):152-5. https://doi. org/10.1038/sj.bjc.6602907.

56. Borg V. Mental health, sick leave and return to work [Danish: Hvidbog om mentalt helbred, sygefravær og tilbagevenden arbejde]. Copenhagen: Arbejdstilsynet, Work Environment in Denmark; 2010

57. Damkjaer LH, Deltour I, Suppli NP, Christensen J, Kroman NT, Johansen C, et al. Breast cancer and early retirement: associations with disease characteristics, treatment, comorbidity, social position and participation in a six-day rehabilitation course in a register-based study in Denmark. Acta Oncol Stockh Swed. 2011;50(2):274-81. https://doi.org/10.3109/0284186X.2 010.531048

58. Sopik V, Sun P, Narod SA. Predictors of time to death after distant recurrence in breast cancer patients. Breast Cancer Res Treat. 2019;173(2): 465-74. https://doi.org/10.1007/s10549-018-5002-9.

59. PharmGKB. Taxane Pathway, Pharmacokinetics Overview [Internet]. PharmGKB. 2018. [cited 2018 Feb 5]. Available from: https://www.pharmgkb. org/pathway/PA154426155.

60. Sparano JA, Zhao F, Martino S, Ligibel JA, Perez EA, Saphner T, et al. Longterm follow-up of the E1199 phase III trial evaluating the role of taxane and schedule in operable breast cancer. J Clin Oncol Off J Am Soc Clin Oncol. 2015;33(21):2353-60. https://doi.org/10.1200/JCO.2015.60.9271.

\section{Publisher's Note}

Springer Nature remains neutral with regard to jurisdictional claims in published maps and institutional affiliations.

\section{Ready to submit your research? Choose BMC and benefit from}

- fast, convenient online submission

- thorough peer review by experienced researchers in your field

- rapid publication on acceptance

- support for research data, including large and complex data types

- gold Open Access which fosters wider collaboration and increased citations

- maximum visibility for your research: over $100 \mathrm{M}$ website views per year

At BMC, research is always in progress.

Learn more biomedcentral.com/submissions 